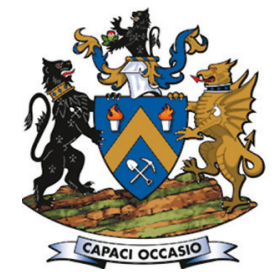

Affiliation:

1 University of Pretoria, Pretoria South Africa.

${ }^{1}$ Council for Scientific and Industrial Research (CSIR), Pretoria, South Africa.

Correspondence to:

E. van der Lingen

Email:

elma.vanderlingen@up.ac.za

Dates:

Received: 13 Feb. 2020

Revised: 31 Aug. 2020

Accepted: 29 Sep. 2020

Published: November 2020

How to cite:

Roux, R.N., Van der Lingen, E.,

Botha, A.P., Botes, A.E. 2020

The fragmented nature of the

titanium metal value chain.

Journal of the Southern African

Institute of Mining and Metallurgy,

vol. 120 , no. 11 , pp. $633-640$

DOI ID:

http://dx.doi.org/10.17159/2411-

9717/1126/2020

ORCID

E. van der Lingen

https://orchid.org/0000-0003-

1648-3564

\title{
The fragmented nature of the titanium metal value chain
}

\author{
R.N. Roux ${ }^{1,2}$, E. Van der Lingen ${ }^{1}$, A.P. Botha ${ }^{1}$, and A.E. Botes ${ }^{2}$
}

\section{Synopsis}

This study investigates the fragmented nature of the global and local titanium metal value chains. South Africa has the fourth most abundant titanium reserves in the world. However, South Africa mainly exports titanium ore and imports value-added titanium products, which impacts the potential to derive more economic benefit from this resource. For South Africa to benefit from its titanium reserves, an understanding of the current fragmented nature of the global titanium value chain would assist in entering the global titanium industry. Information on the global and South African titanium value chains was collected by means of a desktop study. It was found that the leading countries operating within both the upstream and the downstream titanium industry are the USA, China, Japan, Russia, and Kazakhstan. The key drivers that caused fragmentation were identified as technology, markets, production costs, and the availability of titanium mineral reserves. An important outcome of this study is the identification of the local need for a technological foundation in support of downstream titanium processing to marketcompetitive titanium mill and powder products.

\section{Keywords}

fragmentation, titanium, titanium value chain.

\section{Introduction}

Titanium is found in most countries and is the ninth most abundant element in the Earth's crust (Tarselli, 2013). However, in its metallic form titanium is one of the world's scarcest and most expensive structural metals (Abkowitz et al., 1990; Woodruff and Bedinger, 2013). Titanium is mined in several countries, but the difficulty of refining the ore has contributed to a fragmented global titanium value chain. According to Cardarelli (2013) the fragmentation is notable due to the long distances between titanium mining companies and the companies that supply the market with finished products.

Although South Africa is one of the leading titanium mining countries (USGS, 2018), the country is not benefitting optimally from this resource through beneficiation. After mining of titanium minerals (rutile and ilmenite), South Africa exports ilmenite slag (titania) and upgraded natural rutile, mainly to be used for titanium pigment production (Roskill, 2013; WITS, 2018). Minor quantities of rutile are exported to Japan and the USA to be used for titanium sponge production (Roskill, 2013). South Africa does not produce titanium metal, but imports it as powder, mill products, and final products (mainly for the industrial, medical, and consumer markets) (Roskill, 2013, 2019).

The aims of this study were to identify:

Countries with a fragmented titanium metal value chain

- Countries with a complete titanium metal value chain

- The reasons why certain countries have a complete or fragmented titanium metal value chain

- South Africa's current stance with regards to the global titanium metal value chain

- The gaps in the South African titanium metal value chain.

\section{Background}

The high cost of titanium metal is related to its reactivity. This high cost is a consequence of the high production cost and low yield of metal (Bordbar, Yousefi, and Abedini, 2017). Titanium is not present in its metallic state in nature and the purification process is lengthy and expensive (Tarselli, 2013). 


\section{The fragmented nature of the titanium metal value chain}

Approximately $95 \%$ of titanium mined is used to produce white $\mathrm{TiO}_{2}$ pigment, and little is available for titanium metal production (Bordbar, Yousefi, and Abedini, 2017). Nevertheless, the properties of titanium metal make it the material of choice for selective applications within niche high-value industries. Titanium has an exceptional corrosion resistance to a broad range of alkalis, acids, industrial chemicals, and natural waters. The metal is resistant to corrosion attack by salt water and marine atmosphere. Compared to most metals, titanium has a superior resistance to erosion, but this depends on the severity of the erosion as well as the energy of the impacting particles. Titanium is biocompatible and the metal and its alloys are used, for example, in various prosthetic implants. The metal has a superior strength-to-weight ratio (Abkowitz et al., 1990), which makes it highly suitable for jet engines and airframes, and also for ship structures, pumps, deep sea submersibles, condensers, water-jet propulsion systems, weapon systems, fuel gas desulphurization, steam turbines, fan blades, piping systems (e.g. chemical industry), biomedical parts, and compressor discs (Abkowitz et al., 1990).

Titanium is mined as an enriched ore that undergoes several processing stages to produce a finished titanium product. All of the production stages can be divided into three main sections, namely raw material, the processes and technologies, and finally finished products for the market (Du Preez, Damm, and Jordaan, 2013). The three sections can be further subdivided into the eight production stages (Roux, Van der Lingen, and Botha, 2019). Each stage is dependent on its specific precursor and in turn is needed to produce the input for the next stage. This outlines the titanium metal product value chain and is illustrated in Figure 1.

Stage 1 represents the titanium minerals or reserves. Stage 2 is the production of titanium slag or synthetic rutile by upgrading/purifying the natural raw minerals containing titanium. Stage 3 is the production of titanium tetrachloride $\left(\mathrm{TiCl}_{4}\right)$, which is the precursor for both titanium pigment and titanium metal production. Stage 4 represents the production of titanium sponge, which is (to an extent) a form of pure titanium metal. During sponge production $\mathrm{TiCl}_{4}$ is reduced with magnesium (the Kroll process) or sodium (the Hunter process). Stage 5 is the melting process to produce ingots, blooms, billets, and slabs, which are processed forms of titanium sponge. Stage 6 involves the production of intermediate and final mill products, e.g. sheet, plate, bar, wire, and forgings used in the fabrication of final parts and products. The latter also form part of stage 6 as per the Roskill (2019) reference to mill products as finished or part-finished components used by consumers. Stage 7 involves titanium metal powder. The dotted lines shown in Figure 1 indicate alternative routes that can be followed to produce titanium metal powder. The route from stage 3 $\left(\mathrm{TiCl}_{4}\right)$ to stage 7 (titanium powder) is the Armstrong process, a direct electrochemical reduction process, whereas powder production from stage 4 (sponge) could, for example, be by the hydrogenation-dehydrogenation $(\mathrm{HDH})$ process. The dotted red lines from stages 1 and 2 represent processes that are still in the research phase world-wide, aimed at establishing a route to produce titanium powder directly from slag and/or minerals; no commercial process is currently available. Titanium powder (stage 7) can also be produced directly from titanium rods (stage 6) by the plasma-rotating electrode process (PREP). Stage 8 is the production of components/parts and final products from titanium metal powder. A complete titanium metal product value chain can thus end at stage 6 with mill products/parts or stage 8 with powder products/parts.

The global titanium value chain can be described as being fragmented. Fragmentation is the geographical separation of activities involved in producing either goods or services across two or more countries (Athukorala and Yamashita, 2007). Production fragmentation differs from the standard trade data analysis, which is based on the exchange of goods that are produced (start to finish) in one country (Athukorala and Yamashita, 2007). Linking this definition to the fragmented titanium value chain means that titanium mined in a specific country would not necessarily be processed to a finished marketready product in that same country. Thus at some stage of the value chain a raw titanium product is exported from its country of origin to be processed in a second and/or third country, only to be imported back into the origin country as a final high-cost product.

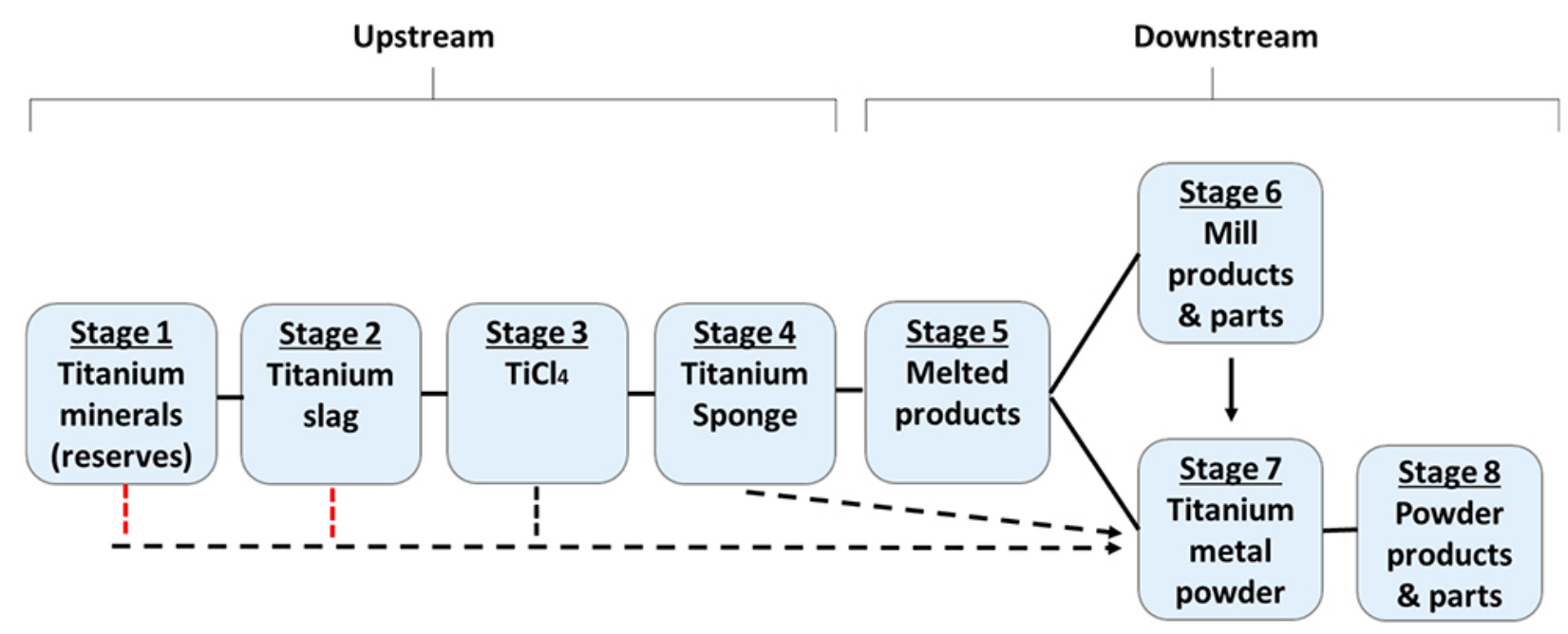

Figure 1-The titanium metal product value chain (modified from Roux et al., 2019). The dotted lines represent alternative routes that can be followed. The red dotted lines represent routes that are not yet commercially applied 


\section{The fragmented nature of the titanium metal value chain}

This study investigated the fragmented nature of the global and South African titanium value chains to identify the countries that have a complete titanium value chain and those with a fragmented titanium value chain. Where available, information was gathered on the causes of the fragmentation and factors that promote a complete titanium metal value chain.

\section{Method}

Information by means of secondary data was collected through a desktop study. Limited information has been published on the fragmented nature of the titanium value chain, and this study made use of peer-reviewed journal articles, company websites, news articles, reports, and books.

The major countries involved in each stage of the titanium metal value chain were identified (Figure 1), based on a keyword search for each stage of the titanium metal value chain. The countries that had sufficient representation to draw conclusions on their value chain status were then identified, and their involvement in the titanium metal value chain studied. Eleven countries were selected based on sufficient information in the literature.

In order to ascertain the fragmented nature of the titanium metal value chain, a matrix was produced to indicate which stages of the titanium metal value chain each of the identified countries were involved in, and which ones not. An example of this matrix is presented in Table I.

The shaded blocks represent stages of the value chain that are commercially active in the specific country (on a commercial production scale, and not pilot plants), and unshaded blocks represent no commercial activity. It should be noted that only titanium metal and related processes were considered. For instance, if a country produced $\mathrm{TiCl}_{4}$ for pigment, but not for titanium metal production, the $\mathrm{TiCl}_{4}$ stage for that specific country would be shown as unshaded. Under stage 7, powder production, $\mathrm{DE}$ refers to powder production by the direct electrochemical method, and SP from titanium sponge.

A complete value chain for a country would be established if a country is able to beneficiate the mined ore to a finished part/ product (mill or powder) without importing or exporting along the value chain (this excludes imports and exports due to demand or surplus conditions). Different routes could be followed to reach a final product, as indicated in Figure 1. Once the countries were identified and their value chains determined (fragmented or not), the reasons for the fragmented or complete value chain were investigated.

\section{Results and discussion}

\section{The fragmented titanium metal industry}

More than 15 countries are mining titanium, with the top five being Australia, Canada, China, South Africa, and Mozambique (Dewhurst, 2013; USGS, 2018). The mined production quantities for Canada and China are fairly equal, as well as for South Africa and Mozambique. Possession of economically viable reserves of titanium minerals does not guarantee that a country will have a thriving titanium industry (Abkowitz et al., 1990). Stages 1 (mineral reserves and mining) and 2 (mineral upgrading) of the value chain (Figure 1) make use of well-developed processes. Mining is mostly conducted on natural concentrated heavymineral deposits (placer deposits) with an average titanium recovery rate of $90 \%$. After mining, the material (depending on the quality) undergoes processing (such as oxidation, reduction, leaching, screening, and magnetic separation) to improve the purity (van Tonder, 2010) and this is referred to as upgrading (stage 2). These first two stages are globally at a mature level with regard to the technology required.

Fragmentation is observed from stage 3 onward, which is the production of $\mathrm{TiCl}_{4}$ through the chloride process. The bulk of the $\mathrm{TiCl}_{4}$ produced is used in the production of titanium pigment, and smaller quantities of high-quality $\mathrm{TiCl}_{4}$ are used to produce titanium metal (Van Vuuren, 2009; Van Tonder, 2010). South Africa's titanium metal value chain is fragmented from stage 3 as the country does not have the technology to produce $\mathrm{TiCl}_{4}$. Australia processes most of its titanium to low-quality $\mathrm{TiCl}_{4}$ for pigment production. This low-quality $\mathrm{TiCl}_{4}$ is not suitable for titanium metal production, although it can be further purified to metal grade (Tronox, 2020). According to Balinski (2015), Coogee Chemicals in Australia can produce a metal-grade $\mathrm{TiCl}_{4}$ feedstock using fluidized bed technology on a pilot scale.

Stage 4 of the titanium metal value chain incorporates mainly the Kroll process. This is the leading commercial process, producing approximately $99 \%$ of the world's titanium metal, and is referred in the literature as the conventional titanium production method (Nagesh et al., 2004; Van Tonder, 2010). Over the years several advancements on the Kroll process have been proposed, but the standard Kroll route remains the preferred titanium metal producing process. Globally, eight countries produce titanium sponge, mainly via the Kroll process. These countries are China, India, Japan, Kazakhstan, Russia, the USA, Ukraine, and most recently Saudi Arabia (Dewhurst, 2013; Asian Metal, 2014; Roskill, 2019). Among the sponge producing

Table I

Matrix indicating fragmentation within the titanium metal value chain

\begin{tabular}{|c|c|c|c|c|c|c|c|c|}
\hline Country & Stage 1 & Stage 2 & Stage 3 & Stage 4 & Stage 5 & Stage 6 & Stage 7 & Stage 8 \\
\hline 1 & & & & & & & SP & \\
\hline 2 & & & & & & & SP & \\
\hline 3 & & & & & & & & \\
\hline 'n' & & & & & & & $\mathrm{DE} / \mathrm{SP}$ & \\
\hline
\end{tabular}




\section{The fragmented nature of the titanium metal value chain}

countries, India and Saudi Arabia are not investigated further in this article as limited information was obtained during the literature search. Only one plant in the USA, namely Honeywell Electronic Materials, produces a small amount (approximately $0.3 \mathrm{kt} / \mathrm{a}$ ) of titanium sponge via the Hunter process. This sponge is of very high purity and is used for electronics (Roskill, 2019). Donachie (2000) reported on titanium sponge production in the UK in 2000 , but no mention this was found in the more recent literature. It is important to note that three of the titanium sponge producing countries mine little or no titanium ore (USGS, 2018). These are Russia, Saudi Arabia, and Japan, with Japan having no economic titanium reserves. Russia, on the other hand, has no rutile deposits and the ilmenite deposits that are mined have no compositional equivalents elsewhere (Sokolov, 2011). Russia is therefore dependent on new and unique technologies to make mining and upgrading of its reserves profitable and sometimes purchases raw titanium materials from the former Soviet Union countries at huge cost to fulfil demand (Kukhmazov, 2016). Saudi Arabia, on the other hand, has only titanium resources and no reserves. These three countries import ore and chlorinate it locally to produce titanium sponge.

Limited academic literature is available, specifically on countries that participate in stage 5 (melted products) and stage 6 (mill products) of the value chain. According to the 2019 Roskill report the production of titanium sponge and the subsequent melted product step are mostly done on the same site (Roskill, 2019). Once the titanium sponge is processed into titanium melted products it can be shipped anywhere in the world for further processing. The Roskill report also states that there is limited global trade in melted products as these are mostly further processed to mill products (stage 6) on the same site or in the same country (Roskill, 2019). The top countries for mill product output in 2017 were China, the USA, Russia, Japan, and unspecified countries in Europe (Roberts, 2018).

Stage 7 in the titanium metal value chain is the production of titanium metal powder. This could either be by crushing of titanium sponge (the conventional method) or by the direct titanium powder production route which is under development by several nations. The global leading titanium metal powder producers are the USA, China, Japan, and Europe (QY Research Group, 2017). The bulk of titanium metal powder is produced from titanium sponge precursor and the most popular processes used are HDH, gas atomization, and PREP (Oh et al., 2014). The countries currently producing titanium powder from titanium sponge are the USA, Japan, China, Russia, Australia, Ukraine, Canada, France, Germany, Sweden, and the UK (Moxson, Senkov, and Froes, 2000; QY Research Group, 2017; Roskill, 2019; Titanium Institute, 2019). Coogee Chemicals in Australia commissioned a $200 \mathrm{t} / \mathrm{a}$ titanium alloy powder demonstration production facility in 2019. This facility uses the same chemistry as the Kroll process but runs on a continuous rather than a batch basis, and produces a powder product instead of titanium sponge. The technology was developed by the CSIRO using the TiRO method (Doblin, Freeman, and Richards, 2013).

The direct production of titanium metal powder has been identified as a viable way to reduce the high production cost of titanium metal (Bolzoni, Ruiz-Navas, and Gordo, 2017). This cost reduction can be attributed to two main aspects. The first is the direct reduction of the host mineral or an intermediate precursor $\left(\mathrm{TiCl}_{4}\right)$ to titanium metal powder (Roskill, 2013). The second is the reduced cost for processing and manufacturing of the powder compared to the conventional metallurgical route (Bolzoni, Ruiz-Navas, and Gordo, 2017). The leading producer of titanium metal powder by direct electrochemical reduction is the USA, through the Armstrong process. The Armstrong process had the capacity to produce $1800 \mathrm{t}$ annually in 2019 (Roskill, 2019). The second country to consider is Australia with the TiRO process. Although this process is based on Kroll sponge principles the end product is a titanium metal powder.

Several other countries are developing a method to produce titanium powder (Whittaker, 2012). The leading countries are:

> The UK with the Metalysis process, formerly known as the Fray-Farthing-Chen or FFC process (Okabe, Oda, and Mitsuda, 2004; Chunxiang et al., 2011; Metalysis, 2019). Although successes have been reported, there was no production capacity in 2019 as the company encountered financial trouble.

> The CSIR-Ti process being developed in South Africa (Whittaker, 2012; Roskill, 2019).

> The Preform Reduction process and its variation the OnoSuzuki process, being developed in Japan (Okabe, Oda, and Mitsuda, 2004).

The final stage of the titanium metal value chain (stage 8) is the production of finished products or parts from titanium powder by means of powder metallurgy (PM). This is an innovation that allows for a reduced cost as well as improved performance of the part while shortening the development and production cycle times (Gabriele, 2018). One of the leading developments within stage 8 of the titanium metal value chain is additive manufacturing (AM), which can also be applied to metal wire instead of powder. Powder quality, purity, morphology, and particle size influence the mechanical properties of the final product and its application (Goso and Kale, 2011; Fang et al., 2017). Producers will therefore only manufacture parts according to demand (based on the local or export market) and the technology available to them. Similar to the trend for mill products, it is difficult to trace which countries produce titanium powder products as the technology is readily available. Titanium powder and mill products are readily available on the market and are used in the production of final products for several established industries, such as the automotive, aerospace, biomedical, and petrochemical industries (QY Research Group, 2017).

\section{Titanium metal value chain fragmentation}

Eleven countries were identified as the main countries involved in the global titanium metal industry. In order to determine the fragmentation of the titanium metal value chain within these countries, the fragmentation matrix described under the Methodology section was applied. The results, based on the eight stages of the titanium metal value chain, are presented in Table II.

Table II indicates that five of the 11 selected countries have completed titanium metal value chains. These countries are China, Russia, Kazakhstan, Ukraine, and the USA. China, Russia, the USA, and Kazakhstan are the only four countries that are involved in all eight stages of the titanium metal value chain. Ukraine does not produce titanium metal powder, but 


\section{The fragmented nature of the titanium metal value chain}

\begin{tabular}{|c|c|c|c|c|c|c|c|c|}
\hline \multicolumn{9}{|c|}{$\begin{array}{l}\text { Table II } \\
\text { Fragment } \\
\text { direct elec }\end{array}$} \\
\hline Country & $\begin{array}{l}\text { Stage 1: } \\
\text { Ti reserves }\end{array}$ & $\begin{array}{l}\text { Stage 2: } \\
\text { Ti slag }\end{array}$ & $\begin{array}{l}\text { Stage 3: } \\
\mathrm{TiCl}_{4}\end{array}$ & $\begin{array}{c}\text { Stage 4: } \\
\text { Ti sponge }\end{array}$ & $\begin{array}{c}\text { Stage 5: } \\
\text { melted products }\end{array}$ & $\begin{array}{l}\text { Stage 6: } \\
\text { mill products }\end{array}$ & $\begin{array}{l}\text { Stage 7: } \\
\text { Ti powder }\end{array}$ & $\begin{array}{c}\text { Stage 8: } \\
\text { powder products }\end{array}$ \\
\hline Australia & & & & * & & & * & \\
\hline Canada & & & & & & & SP & \\
\hline China & & & & & & & $\mathrm{SP}$ & \\
\hline Japan & & & & & & & SP & \\
\hline Kazakhstan & & & & & & & $\mathrm{SP}$ & \\
\hline \multicolumn{9}{|l|}{ Mozambique } \\
\hline Russia & & & & & & & SP & \\
\hline \multicolumn{9}{|l|}{ South Africa } \\
\hline \multicolumn{9}{|l|}{ Ukraine } \\
\hline UK & & & & & & & $\mathrm{DE}$ & \\
\hline USA & & & & & & & $\mathrm{DE} / \mathrm{SP}$ & \\
\hline
\end{tabular}

${ }^{*}$ The TiRO process is based on Kroll sponge principles and produces a titanium metal powder, and not a titanium sponge.

also qualifies as a country with a full value chain for mill end products. China (together with Russia, Japan, Kazakhstan and the USA) produces powder from titanium sponge, while the USA and the UK are following the direct electrochemical route. Limited feedstock from ilmenite mines is supplied to Russian titanium sponge producer VSMPO-Avisma, which requires this plant to have $\mathrm{TiCl}_{4}$ production capacity (TZMI, 2012).

Australia, Canada, and South Africa are currently experiencing similar fragmentation at stages 4 and 5 . These three countries have large titanium reserves but export the raw material and import processed titanium at a higher cost. These countries have established some downstream processing capability in titanium metal, in contrast to Mozambique which is only involved in the first two stages of the titanium metal value chain.

Japan does not have titanium mineral reserves, but is involved in the remainder of the value chain. Japan produces titanium metal powder from titanium sponge and is also researching the production of powder through direct electrochemical techniques. The UK imports ingots and metal oxide powder to produce both mill products and titanium powder products.

\section{Fragmentation of the South African titanium metal value chain}

South Africa is one of the largest producers of mined titanium (rutile and ilmenite) (Woodruff and Bedinger, 2013; USGS,

2018). Based on this, one would assume that the country has a thriving titanium industry, but the technological gap for further processing (post-mining) to high-value downstream products is large. South Africa does not have a complete titanium metal value chain and the country is involved in only four of the value chain stages on a commercial level. Two of these stages fall within the upstream, and two within the downstream, of the value chain (Roux et al., 2019). The fragmented South African titanium metal value chain is presented in Figure 2.

The blue shaded blocks in Figure 2 depict the four stages of the value chain currently operating in South Africa. The white arrows indicate the exports (minerals, slag, mill products, and powder products) and the dark arrows indicate imports (mill products, titanium metal powder, and titanium metal powder and melted products). The grey stage blocks indicate the gaps within the South African titanium metal value chain. These include production of $\mathrm{TiCl}_{4}$, (stage 3), titanium sponge (stage 4), melted products (stage 5), and titanium metal powder (stage 7).

South Africa is involved in stage 1 (mining) and stage 2 (upgrading) in the upstream section of the titanium metal value chain on a commercial level. In the downstream section of the value chain, South Africa is involved with stage 6 and stage 8 on a commercial level. With regard to mill products (stage 6), several South African companies are machining imported ingots and mill products and selling the final products on the local or international markets (Daliff, 2019; Ti-TA MED, 2019). South Africa is also actively involved in the manufacturing of powder products (stage 8). Several local companies are fabricating specialized parts from titanium metal powder. One of the most 


\section{The fragmented nature of the titanium metal value chain}

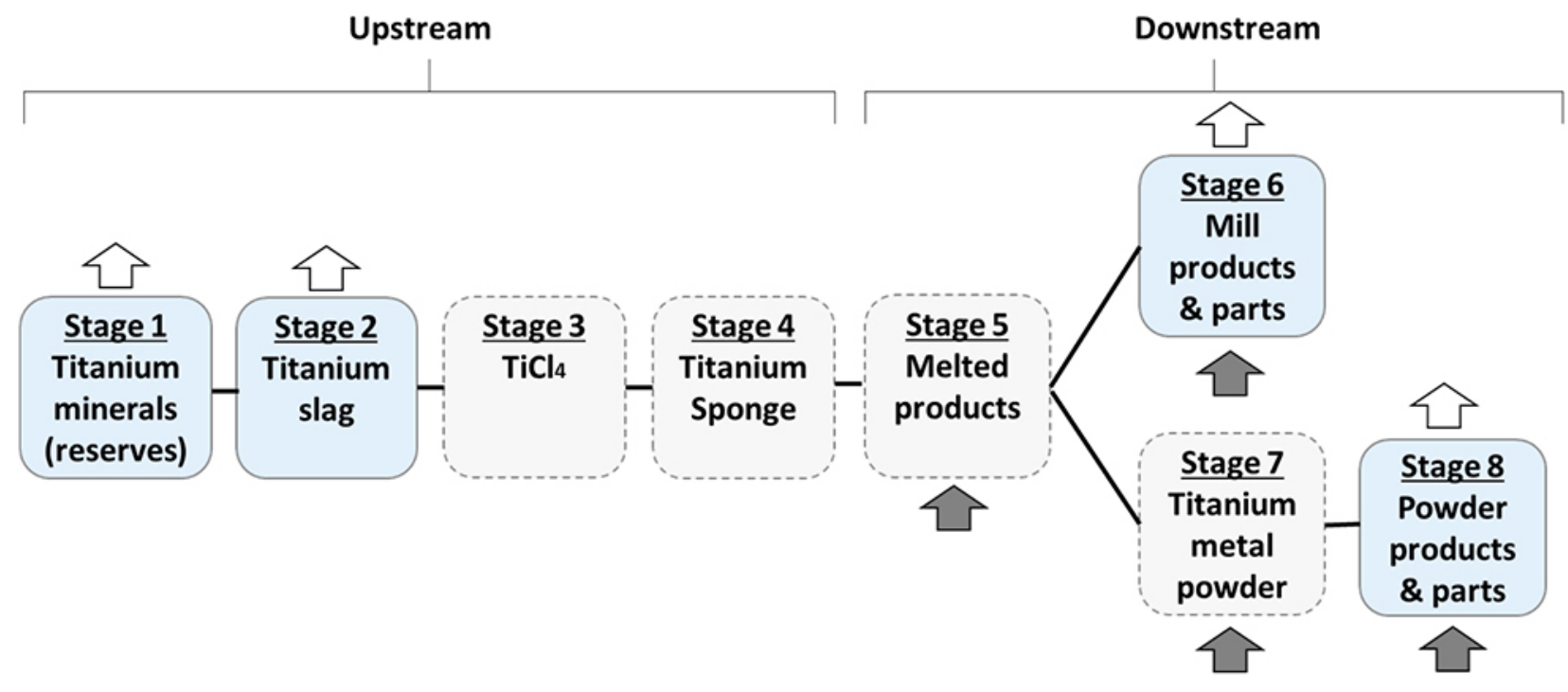

Figure 2-The South African titanium metal product value chain (modified from Roux et al., 2019)

well-known examples of this is the Aeroswift project. The Aeroswift machine is a high-speed AM machine that is able to produce very large and complex parts for aerospace and other industries (Department of Trade and Industry, 2017).

Developing the titanium industry in South Africa by filling the value chain gaps is envisaged carrying large socio-economic benefits for the local industry, the government, and the people of South Africa (Rokita, 2017). The development of the titanium industry falls under one of South Africa's Key Action Plans as set out in the annual Industrial Policy Action Plan (IPAP) report (Department of Trade and Industry, 2014). This report highlights the country's vision to improve and upscale its industrial development objectives. The IPAP action plans are addressed by a collaborative effort between the DST (Department of Science and Technology; now DSI - Department of Science and Innovation), and the dti (Department of Trade and Industry; now dtic Department of Trade, Industry and Competition) (Department of Trade and Industry, 2014). Although only four stages of the value chain are represented on an industrial level, research is ongoing locally on every stage of the titanium metal value chain.

\section{Possible reasons for fragmentation of the titanium metal-value chain}

From Table II, six countries with fragmented titanium metal value chains were identified. The reasons for fragmentation within these six countries are rarely similar, although some overlap and duplication occurs. The identified reasons for the fragmention are the complexity of the metal production process, the (low) purity of the mineral feedstock, environmental concerns, availability of the required technologies, distance to the market, as well as the absence of economic titanium mineral reserves. Each of these possible reasons, with examples taken from the six countries, are discussed.

\section{Complexity of metal production process}

The complexity of producing titanium metal adds to the production cost at every stage of the titanium metal value chain.
The production of titanium metal involves a number of complex steps to get from the raw mineral to a metal product. The reactivity of titanium is the major reason for the complexity and necessitates expensive processing steps. The metal must be not only purified of the inherent contaminants, but also prevented from reacting with external contaminants. In order to ensure that a high-quality product is obtained, the titanium should be protected from reacting with other elements during most stages of the value chain. This could be achieved by working in a vacuum or an inert atmosphere. Examples include vacuum distillation during titanium sponge production (stage 4), vacuum arc re-melting during ingot production (stage 5), working under an inert atmosphere with titanium powders during the HDH process (stage 7), during vacuum plasma spraying (stage 8), and vacuum annealing of titanium alloys (stage 6) to produce pure finished products (Roskill, 2013; Oh et al., 2014; Fang et al., 2018). Countries that lack the necessary skills and technologies are particularly challenged to successfully conduct the complex processes for manufacturing titanium powder. These countries do not have the resources to process titanium metal or powder, and thus export raw material to be processed elsewhere.

\section{Purity of the mineral feedstock}

The general precursor for titanium metal is $\mathrm{TiCl}_{4}$, which is expensive compared to the feedstocks for aluminium and steel production (Roskill, 2019). Although $\mathrm{TiCl}_{4}$ is expensive, it is the most effective and practical intermediate for titanium metal production (Van Tonder, 2010). The issue here is that the quality of the $\mathrm{TiCl}_{4}$ is determined by the impurities present in the titanium minerals used during chlorination, and therefore if the feedstock is contaminated it might not be possible, or too expensive, to produce pure titanium metal from the $\mathrm{TiCl}_{4}$ (Dooley, 1975). Alternative methods, which replace $\mathrm{TiCl}_{4}$ as the precursor for titanium metal, are currently being researched. These include the Fray-Farthing-Chen (FFC)-Cambridge process and the EMR/ MSE (Electronically Mediated Reaction/Molten Salt Electrolysis) process, but the overall cost reduction is limited (Van Tonder, 


\section{The fragmented nature of the titanium metal value chain}

2010). Examples of countries in which titanium metal production has been influenced by $\mathrm{TiCl}_{4}$ purity include Australia and Russia. Before the commercialization of the TiRO process Australia did not produce a pure enough $\mathrm{TiCl}_{4}$ to be used in titanium metal production. Russia, on the other hand, has low-quality titanium reserves and only a small portion of local ilmenite is suitable for metal production. Russia is highly dependent on titanium mineral imports to sustain its titanium industry.

\section{Environmental concerns}

Environmental concerns could also contribute to the fragmented nature of the titanium metal industry. During the production of metals, emission of unwanted solids, liquids, and gases are produced (Norgate, Jahanshahi and Rankin, 2007). The environmental concerns are applicable to several stages of the production value chain. Ores are often physically beneficiated and undergo chemical transformation in order for the metal to be extracted to produce the industrial-grade material required. The amount of energy required is also an aspect that needs to be considered, together with the use of reagents, water, and fuel. The toxicity of the reagents used is also a concern (Norgate, Jahanshahi, and Rankin, 2007). This reason affects every stage of the titanium metal value chain and therefore all the countries in the study.

\section{Availability of technology}

The availability of technologies to process titanium also contributes to the fragmented nature of the titanium value chain, especially stages $3,4,5$, and 7 . The availability of new technology overlaps with the high cost of obtaining existing technology, the environmental impact of applying the technology, as well as the development of new types of technologies that would reduce the cost of titanium metal production. This reason for fragmentation is applicable to all the countries that export their mineral reserves and import value-added products, e.g. South Africa, Australia, Canada, and Mozambique.

\section{Distance to the market}

The major consumers of titanium metal are China, North America, Europe, Russia, and Japan, as well as the combined markets of South Korea and Taiwan (Roberts, 2018). These consumers are located large distances from some of the major titanium mining countries such as South Africa, Australia, and Mozambique. These mining countries do not necessarily have a large enough market to consume the mined and upgraded minerals locally, and this opens up trading opportunities with other countries.

\section{Absence of economic titanium reserves}

Some countries such as Japan and the UK do not mine titanium minerals and are dependent on imports. The absence of economic titanium reserves is the major reason why these countries have a fragmented titanium metal industry.

\section{Conclusions}

The global titanium metal industry is fragmented. Only five of the countries investigated have complete titanium metal value chains. These are China, Kazakhstan, Russia, Ukraine, and the USA. Of these countries, only four are involved in every stage of the mill product and powder product value chains - China, Kazakhstan, Russia, and the USA. South Africa is one of the countries with a fragmented titanium metal value chain. The South African government is striving to promote research on the remainder of the value chain phases, but in order to do this, the gaps and possible reasons for fragmentation first need to be addressed.

The results from this study are based on 11 countries that are involved in the global titanium metal value chain. The fragmented nature of the value chain was analysed based on country-specific fragmentation. This analysis highlighted six possible reasons for global fragmentation within the titanium metal industry:

i. Complexity of the metal production process

ii. Purity of the mineral feedstock

iii. Environmental concerns

iv. Availability of the required technologies

v. Distance to the market

vi. Absence of economic titanium mineral reserves.

Four of these reasons apply to South Africa, namely the complexity of the metal production process (which also includes the cost of the process), environmental concerns, availability of the needed technology, and distance to the market. South Africa needs to evaluate the global markets and decide whether it should continue to strive for a complete titanium metal value chain or focus on improving the stages of the value chain that it is currently involved in. When this decision has been made, South Africa should investigate the four reasons influencing fragmentation and find ways to address these reasons where applicable.

\section{Acknowledgments}

The CSIR Advanced Metals Initiative (AMI) for financial support.

\section{References}

Abrowitz, S., Bannon, B., Broadwell, R., Harvey, B., and Broadwell, R. 1990. Titanium, The Choice. Dayton, Ohio. http://www.byterfly.eu/islandora/object/ librib:110924/datastream/PDF/content/librib_110924.pdf

Asian Metal. 2014. Titanium sponge. http://metalpedia.asianmetal.com/metal/ titanium/titaniumsponge.shtml [accessed: 8 January 2019].

AthuKorala, P. and Yamashita, N. 2007. Production fragmentation in manufacturing trade: The role of East Asia in cross-border production networks. Working Papers Series no.003. Centre for China and Asian Studies, College of Economics, Nihon University, Tokyo. http://citeseerx.ist.psu.edu/viewdoc/ download?doi=10.1.1.509.9926\&rep=rep1\&type=pdf

BaLinski, B. 2015. Manufacturers monthly material of the month Part 4: Titanium, Manufacturers Monthly. https://www.manmonthly.com.au/features/ manufacturers-monthly-material-of-the-month-part-4-titanium/ [accessed: 6 February 2020].

Bolzoni, L., RuIz-Navas, E.M., and GoRdo, E. 2017. Quantifying the properties of lowcost powder metallurgy titanium alloys. Materials Science \& Engineering A, 6 vol. 687. pp. 47-53. doi: 10.1016/j.msea.2017.01.049

Bordbar, H., Yousefi, A A.. and Abedini, H. 2017. Production of titanium tetrachloride $\left(\mathrm{TiCl}_{4}\right)$ from titanium ores : A review. Polyolefins Journal, vol. 4, no. 2., pp. 149-173. doi: 10.22063/POJ.2017.1453

Cardarelli, F. 2013. Materials Handbook. 3rd edn. Springer, Canada.

Chunxiang, C., BaoMin, H., Lichen, Z., and Shuangin, L. 2011. Titanium alloy production technology, market prospects and industry development. Materials \& Design, vol. 32, no. 3. pp. 1684-1691. 


\section{The fragmented nature of the titanium metal value chain}

DALIFF. 2019. Daliff Precision Engineering. https://www.daliff.co.za/ [accessed: 3 June 2016].

Department of Trade and Industry. 2014. Industrial Policy Action Plan 2014/ 15 -. 2016/17.Pretoria. https://www.idc.co.za/wp-content/uploads/2019/02/ IPAP2014.pdf

Department of Trade and Industry. 2017. Industrial Policy Action Plan, 2017/182019/20.Pretoria. https://www.gov.za/documents/industrial-policy-action-planipap-201718-201920-26-apr-2017-0000

Dewhurst, P. 2013. Untitled. Titanium Sponge Supply. Roskill, Las Vegas, NV., p. 32. https://cdn.ymaws.com/titanium.org/resource/resmgr/2010_2014_ papers/DewhurstPhilipTiUSA2013Suppl.pdf

Doblin, C., Freeman, D., and Richards, M. 2013. The TiRO ${ }^{\mathrm{TM}}$ process for the continuous direct production of titanium powder. Key Engineering Materials, vol. 551 doi: 10.4028/www.scientific.net/KEM.551.37

DonAchiE, M.J.J. 2000. Titanium. A Technical Guide. 2nd edn. ASM International, Cleveland, $\mathrm{OH}$.

DooLey, G.J. 1975. Titanium production: ilmenite vs. rutile. Journal of Metals, vol. 27, no. 3. pp. 8-16.

Du Preez, W., Damm, O., and JordaAn, J. 2013. Titanium milled products: roadmap for SA. CSIR, Pretoria.

Fang, Z.Z., Paramore, J. D., Sun, P., Chandran, K.S.R., Zhang, Y., Xia, Y., Cao, F. Koopman, M., and Free, M. 2017. Powder metallurgy of titanium - past, present, and future. International Materials Reviews, vol. 63, no. 7. pp. 1-53.

Gabriele, M. 2018. Titanium USA 2018. Executive Summary. Titanium USA 2018. International Titanium Association (ITA). pp. 1-40. https://cdn.ymaws.com/ titanium.org/resource/resmgr/02_jens_folder/titanium_usa_2018_executive_. pdf

Goso, X. and KalE, A. 2011. Production of titanium metal powder by the HDH process. Journal of the Southern African Institute of Mining and Metallurgy, vol. 111, no. 3. pp. 203-210.

Kuкнмаzov, I. 2016. Geologic structure of Gofitsky deposit of titanium and zirconium and perspectives of the reserve base of titanium and zirconium in Russia. Geophysical Research Abstracts, vol. 18. p. 753. https://meetingorganizer. copernicus.org/EGU2016/EGU2016-753.pdf.II

METALYSIs. 2019. Metalysis - Our Missionn-dash. https://www.metalysis.com/ [accessed: 14 May 2019].

Moxson, V.S., Senkov, O.N., and Froes, F.H. 2000. Innovations in titanium powder processing. Journal of the Minerals, Metals and Materials Scociety, vol. 52, no. 5. pp. 24-26. doi: 10.1007/s11837-000-0027-y

Nagesh, C., Sridhar Rao, C., Ballal, N.B., and Krishna Rao, P K. 2004. Mechanism of titanium sponge formation in the Kroll reduction reactor. Metallurgical and Materials Transactions B-Process Metallurgy and Materials Processing Science, vol. 35, no. 1. pp. 65-74. doi: 10.1007/s11663-004-0097-2

Norgate, T.E., Jahanshahi, S., and Rankin, W.J. 2007. Assessing the environmental impact of metal production processes. Journal of Cleaner Production, vol. 15, no. 8-9. pp. 838-848. doi: 10.1016/j.jclepro.2006.06.018

OH, J.-M., Roh, K.-M., Lee, B.-K., Suh, C.-Y., Kiм, W., Kwon, H., and Lim, J.-W. 2014. Preparation of low oxygen content alloy powder from Ti binary alloy scrap by hydrogenation-dehydrogenation and deoxidation process. Journal of Alloys and Compounds, vol. 593. pp. 61-66.

ОкавE, T.H., OdA, T., and MrtsudA, Y. 2004. Titanium powder production by preform reduction process (PRP). Journal of Alloys and Compounds, vol. 364, no. 1-2. pp. 156-163. doi: 10.1016/S0925-8388(03)00610-8

QY ReSEARCH Group. 2017. Global titanium powder market research report 2017. http://www.reportsnreports.com/reports/800353-global-titanium-powdermarket-research-report-2017.html

RoBerTs, J. 2018. Titanium metal- what will the next decade bring? Titanium USA 2018. Roskill, Las Vagas, NV.

RокITA, P.S. 2017. Socio-economic and techno-economic factors associated with establishing a titanium machining industry in South Africa, a qualitative study. MEng thesis, Stellenbosch University.

RoskiLL. 2013. Titanium metal: market outlook to 2018. Las Vagas, NV.

RoskiLl. 2019. Titanium metal: outlook to 2029. 9th edn. Wimbledon, London.

Roux, R. N., VAn der Lingen, E., and Botha, A.P. 2019. A systematic literature review on the titanium metal product value chain. Proceedings of SAIIEneXXXt, Port Elizabeth. pp. 115-133. doi: 10.7166/30-3-2233

Sокоцоv, A.V. 2011. Titanium metal markets and the Russian aviation industry. Problems of Economic Transition, vol. 54, no. pp. 65-78. doi: 10.2753/ PET1061-1991540305

TARselli, M.A. 2013. Titanium tales. Nature Chemistry, vol. 5, no. 6. p. 546.

Ti-TAMED. 2019. Ti-TAMED Presision Engineering. http://www.titamed.co.za/ [accessed: 3 June 2019].

Titanium InstituTe. 2019. Pilot plant and its products. http://timag.org/en/we-produce/ [accessed: 15 May 2019].

Tronox. 2020. Personal communication during PhD interview. Pretoria.

VAn Tonder, W. 2010. South African titanium: Techno-economic evaluation of alternatives to the Kroll process. MSc Eng thesis, Stellenbosch University.

TZMI. 2012. $\mathrm{TiO}_{2}$ feedstock annual review. Victoria Park, WA

USGS. 2018. Mineral Commodity Summaries. https://minerals.usgs.gov/minerals/ pubs/mcs/2018/mcs2018.pdf

VAN VuUREN, D.S. 2009. A critical evaluation of processes to produce primary titanium. Journal of the Southern African Institute of Mining and Metallurgy, vol. 109, no. 8. pp. 455-461. https://www.scopus.com/inward/record. uri?eid=2-s2.0-73849101378\&partnerID $=40 \&$ md5 $=62$ foode8b02ca6c73f3b21 857552 baf1

WhITTAKER, D. 2012. Powder processing, consolidation and metallurgy of titanium. Powder Metallurgy, vol. 55, no. 1., pp. 6-10. doi: 10.1179/174329012X13297 486041231.

WITS (World Integrated Trade Solutions). 2018. South Africa Titanium ores and concentrates exports by country in 2018. https://wits.worldbank.org/ trade/comtrade/en/country/ZAF/year/2018/tradeflow/Exports/partner/ALL/ product $/ 261400$

Woodruff, L. and Bedinger, G. 2013. Titanium-Light, strong, and white. Reston, VA.

The Journal of the Southern African Institute of Mining and Metallurgy 